\title{
Endoscopic and Enzymatic Treatment of Gastric Bezoar with Acetylcysteine
}

A 40-year old woman presented with a 2-week history of nausea, early satiety and eructation. She frequently ingested large amounts of persimmon. She had no history of previous gastric surgery or other diseases. Physical examination was normal. Endoscopy revealed two large $(10 \times 6 \mathrm{~cm} ; 12 \times 6 \mathrm{~cm})$ and hard bezoars in the fundus and lower corpus of the stomach. On repetition of the endoscopy we used an endoscopic retrograde cholangiopancreatography (ERCP) catheter for instillation of acetylcysteine $(30 \mathrm{ml} / 6 \mathrm{gr}$ of acetylcysteine diluted in $30 \mathrm{ml}$ of $\mathrm{NaCl}$ $0.9 \%$ ) into the bezoars. This solution was first administered onto the outside of the bezoars and, as they softened, the catheter was introduced into the center of the bezoars. For the fragmentation procedure a Dormia basket and a polypectomy snare were used (Figure 1). The polypectomy snare proved to be more efficient than the basket, with a greater capacity for cutting and with less probability of sticking to the bezoar (Figure 2 ). The procedure was carried out in two sessions of $30 \mathrm{~min}$ utes each. In the end the bezoars were totally fragmented into small pieces that were not removed. There were no complications. The control endoscopy, 2 weeks later, was completely normal.

Bezoars, which are relatively uncommon and have a reported incidence of $0.4 \%$, can be treated by enzymatic dissolution, mechanical disruption (gastric lavage or endoscopic means) or surgical removal. Different enzymatic preparations have been used, namely cellulase, papain and acetylcysteine [1-4]. These preparations are often difficult to obtain, except for acetylcysteine, which is used for pulmonary pathology and acetaminophen intoxication. Because the phytobezoar mass is frequently cemented with mucus, a mucolytic agent, such as acetylcysteine, can be useful. Few documented cases of treatment of bezoars with acetylcysteine have been reported, and in those cases it was administered by a nasogastric tube [5]. We used a solution of $30 \mathrm{ml}$ of acetylcysteine diluted in $30 \mathrm{ml}$ of saline solution, which was more concentrated than previously described, and instilled it under direct vision. It was well tolerated by the patient with no associated complications related to acetylcysteine. The acetylcysteine softens the bezoars allowing an easier and faster fragmentation by mechanical means, and it is readily available.

\section{F. G. Silva, C. Gonçalves,}

H. Vasconcelos, I. Cotrim

Department of Gastroenterology, Santo André Hospital, Leiria, Portugal

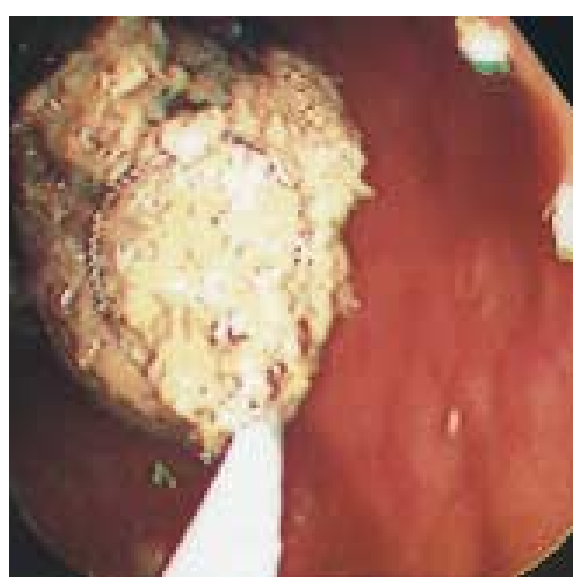
zoar and polypectomy snare.
Figure 1 Endoscopic retrograde cholangiopancreatography (ERCP) catheter into the be-

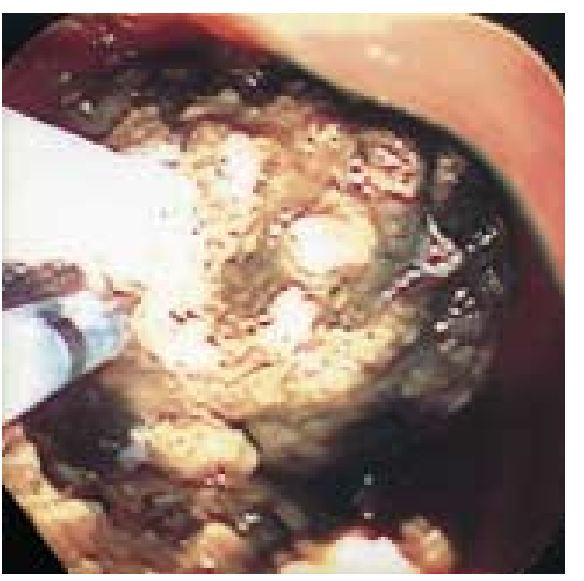

Figure 2 Polypectomy snare cutting the bezoar.

\section{References}

${ }^{1}$ Blam ME, Lichtenstein GR. A new endoscopic technique for the removal of gastric phytobezoars. Gastrointest Endosc 2000; 52: 404-408

2 Lee J. Bezoars and foreign bodies of the stomach. Gastrointest Endosc Clin N Am 1996; 6: 605-619

${ }^{3}$ Walker Renard P. Update on the medicinal management of phytobezoar. Am J Gastroenterol 1993; 88: 1663 - 1666

${ }^{4}$ Kuo JY, Mo LR, Tsai CC et al. Nonoperative treatment of gastric bezoars using electrohydraulic lithotripsy. Endoscopy 1999; 31: $386-388$

${ }^{5}$ Schlang HÁ. Acetylcysteine in removal of bezoar. JAMA 1970; 214: 1329

\section{Corresponding Author}

\section{F. G. Silva, M.D.}

Department of Gastroenterology

Santo André Hospital

Rua das Olhalvas

Pousos

2400 Leiria

Portugal

Fax: $\quad+351-244-817073$ 